\title{
TEM Nanostructure Manipulation Device for in Situ Study of Elastic Behavior of Nanoparticle Chain Aggregates
}

\author{
Y.J. Suh*, S.V. Prikhodko, ${ }^{* *}$ and S.K. Friedlander ${ }^{*}$ \\ *UCLA, Chemical Engineering Dept., Los Angeles, CA 90095 \\ **UCLA, Materials Science and Engineering Dept., Los Angeles, CA 90095
}

Experimental difficulties in studying nanostructures arise from their small size, which limits the use of traditional techniques for measuring their physical properties. We have developed a nanostructure manipulation device (NSMD) (Figure 1) for in situ TEM study of nanoparticle chain aggregates (NCA) under tension. A fine slit was cut in the center of a leadtin alloy disc (specimen support in the Figure 1), measuring $3 \mathrm{~mm}$ in diameter and $200 \mu \mathrm{m}$ in thickness. The disc was heated and pressed between quartz slides. Then it was mechanically dimpled and perforated using ion miller. The edges of the slit were 0.2 to $3 \mu \mathrm{m}$ in thickness while the gap between them was up to a few microns. This disc was bonded to the two plates of a cartridge, which were connected to a commercially available specimen elongating holder (JEOL, EM-SEH, Model IEM100CX-SEH-2). The slit could be widened or narrowed at controlled speeds of 0.5 to $300 \mathrm{~nm} / \mathrm{s}$.

To test the NSMD, we examined titania NCA composed of primary particles about $5 \mathrm{~nm}$ in diameter. The titania NCAs were generated by laser ablation [1] and deposited by diffusion and/or interception from the gas flowing at a velocity of less than $1 \mathrm{~m} / \mathrm{s}$ around the NSMD. Experimental study was done on TEM JEOL JEM-100 CX operated at an accelerating voltage of $100 \mathrm{kV}$. NCA attached to the edges of the slit formed bridge across the slit (Figure 2 (a)). The NCA was stretched at about $0.7 \mathrm{~nm} / \mathrm{s}$ for over 30 minutes as the slit widened. The ends of the NCA remained atached to the sides of the slit during stretching. The length of the NCA was defined as the distance between the two ends attached to the specimen support. Figure 2 shows NCA imagesduring stretching and contraction. The titania NCA stretched up to $176 \%(5.1 \mu \mathrm{m})$; it then contracted rapidly to about $134 \%(3.9 \mu \mathrm{m})$ of its initial length $(2.9 \mu \mathrm{m})$ while remaining in focus. Figure 2 (c) was taken several minutes after the NCA broke and the lower part is out of focus.

The fast contraction after the titania NCA broke was similar to the behavior observed in previous studies using holes in the formvar/carbon supporting films of the TEM grid to produce stretching: the holes resulted from weakening of the film by the electron beam $[1,2]$. The absence of the film in this study confirms that the stretching and contraction observed previously do not require any supporting films. Using NSMD reduces the time required for exposure to the electron beam compared to our previous studies. It makes it possible to study chain aggregates made of materials susceptible to degradation under high energy electron beams. We are currently using the NSMD to study the behavior of carbon NCAs, which are of interest in air pollution (e.g., diesel emissions) and as reinforcing fillers in the manufacture of rubber [3].

\section{References}

[1] K. Ogawa, et al., J. Appl. Phys. 87 (2000) 63.

[2] S.K. Friedlander et al., Appl. Phys. Lett. 72 (1998) 173.

[3] S.K. Friedlander et al., J. Polymer Sci. Part B Polymer Phys. 38 (2000) 2658. 


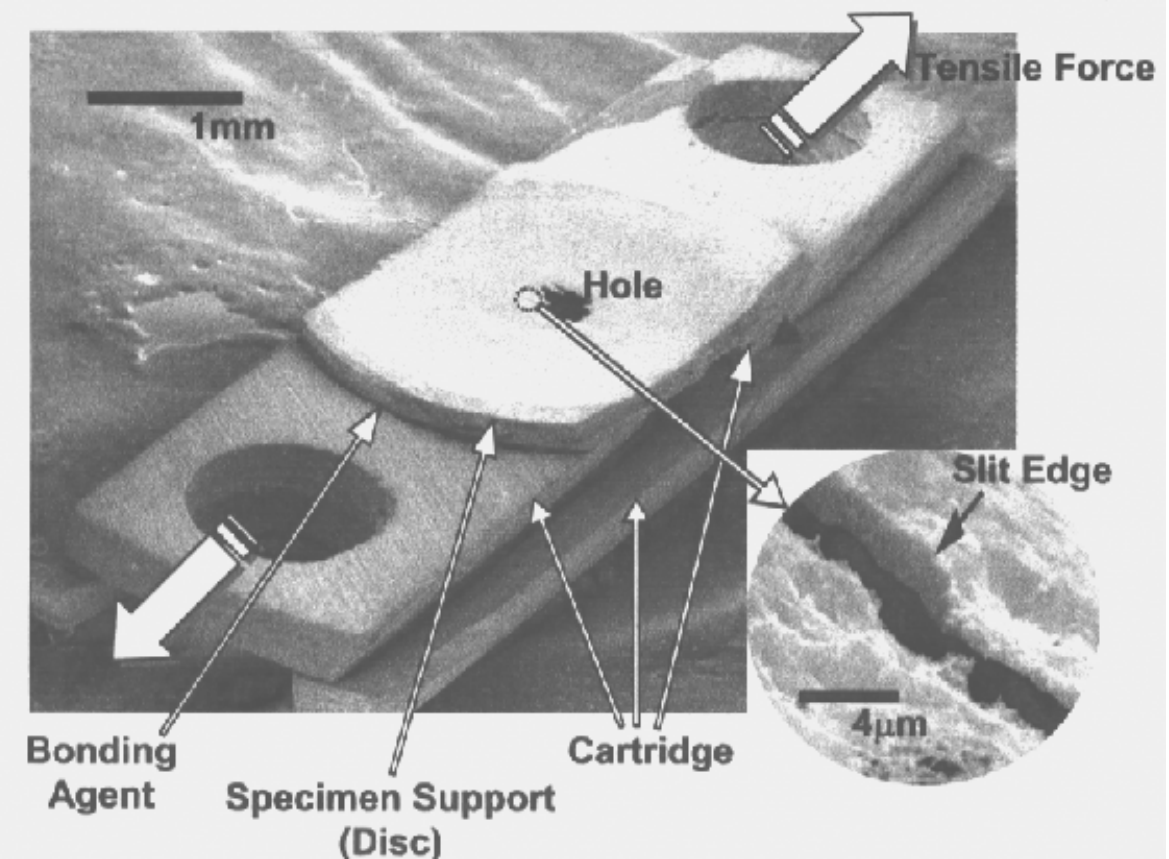

FIG. 1. Nanostructure manipulating device (NSMD). The specimen support had a fine slit and a hole around the center
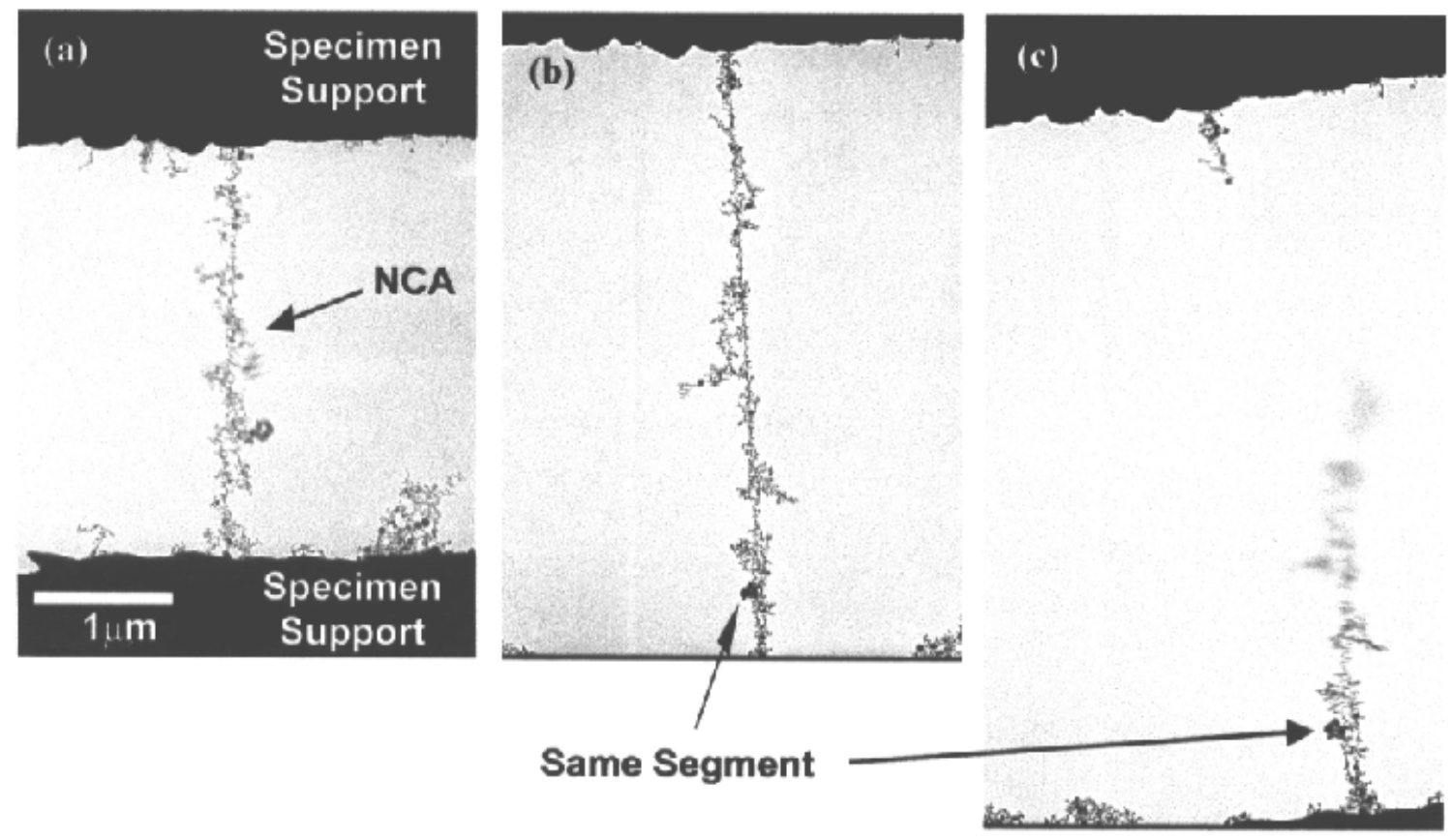

FIG. 2. Stretching and fast contraction of $\mathrm{TiO}_{2}$ on the NSMD. The NSMD was elongated at about $0.7 \mathrm{~nm} / \mathrm{s}$ for over $30 \mathrm{~min}$. Initial end-to-end length of NCA $=2.9 \mu \mathrm{m}(\mathrm{a})$; interim end-to-end length of stretched $\mathrm{NCA} \approx 4.3 \mu \mathrm{m}$, the lower end not shown (b); contracted NCA, end-to-end length of NCA just before contraction $=5.1 \mu \mathrm{m}$, sum of end-to-end lengths of disconnected chain after contraction $\approx 3.9 \mu \mathrm{m}$. 